\title{
Hydrogen mobility in forsterite re- evaluated in the framework of diffusion coupled to inter-site reaction
}

\author{
MICHAEL C. JOLLANDS ${ }^{1}$, JOSHUA MUIR ${ }^{2}$, JOSÉ \\ ALBERTO PADRÓN-NAVARTA ${ }^{3}$ AND SYLVIE \\ DEMOUCHY $^{4}$ \\ ${ }^{1}$ Lamont Doherty Earth Observatory \\ ${ }^{2}$ Institute of Geochemistry, Chinese Academy of Sciences \\ ${ }^{3}$ CNRS \& Univesité de Montpellier \\ ${ }^{4}$ Geosciences Montpellier \\ Presenting Author: jollands@1deo.columbia.edu
}

Whilst the diffusivity of $\mathrm{H}$ in forsterite $\left(\mathrm{Mg}_{2} \mathrm{SiO}_{4}\right)$ has been extensively studied, there still remain some puzzling observations. Firstly, experimental campaigns studying diffusion using different starting materials, experimental geometries, etc., but measuring ostensibly the same process, give different results. Secondly, despite $\mathrm{H}$ diffusion in pure forsterite (over most experimental times (t) and temperatures $(\mathrm{T})$ ) being associated with diffusion of fully hydrogenated $\mathrm{M}$-vacancies $\left(\mathrm{MgH}_{2} \mathrm{SiO}_{4}\right)$, a plethora of different $\mathrm{H}$-bearing point defects have been observed, including hydrogenated $\mathrm{Si}$ vacancies $\left(\mathrm{Mg}_{2} \mathrm{H}_{4} \mathrm{O}_{4}\right)$, defects associated with octahedrally coordinated trivalent cations (e.g. $\left.\left(\mathrm{Cr}^{3+} \mathrm{HSiO}_{4}\right)\right)$, and the so called 'clinohumite-type' point defects, e.g. $\mathrm{MgTi}^{4+} \mathrm{H}_{2} \mathrm{O}_{4}$. The presence of the different defects has been tentatively suggested to some form of inter-site reaction, such as one in which a hydrogenated M-site vacancy (which is capable of diffusing at experimental $\mathrm{Tt}$ ), reacts with a tetrahedrally coordinated $\mathrm{Ti}^{4+}\left(\mathrm{Mg}_{2} \mathrm{Ti}^{4+} \mathrm{O}_{4}\right)$ to form $\mathrm{MgTi}^{4+} \mathrm{H}_{2} \mathrm{O}_{4}$ (which we can assume does not diffuse at the relevant $\mathrm{Tt}$ conditions). Here, we present a series of numerical models in which these processes - diffusion coupled to an inter-site reaction - are simulated. In the models, the mobility of $\mathrm{H}$ is described not only using a diffusion coefficient (D) for the hydrogenated M-site vacancies, but also an equilibrium constant $(\mathrm{K})$ for the relevant inter-site reaction. From a reevaluation of published data, we find that the extracted $\mathrm{D}$ and $\mathrm{K}$ values are remarkably consistent between different datasets, even in situations where the phenomenological D, extracted simply using some solution to Fick's second law, did not agree. We also find that the 'true' mobility of the hydrogenated M-site vacancy must be between 1 and 2 orders of magnitude greater than previously determined, in order to form all observed point defects. Moreover, density functional theory calculations of the $\mathrm{Ks}$ of each of the inter-site reactions implemented in our model, show reasonable agreement with the Ks determined experimentally. These models are complex, but, moving forwards, it may be necessary to assume that measured diffusion profiles in forsterite (and thus natural olivine too) are not formed solely by ionic diffusion. 